\title{
Erratum to: An EQ-5D-5L value set based on Uruguayan population preferences
}

Federico Augustovski $^{1,2}$ - Lucila Rey-Ares ${ }^{1}$ - Vilma Irazola ${ }^{1}$.

Osvaldo Ulises Garay ${ }^{1}$ - Oscar Gianneo ${ }^{3}$ - Graciela Fernández ${ }^{3}$.

Marcelo Morales $^{3} \cdot$ Luz Gibbons $^{1} \cdot$ Juan Manuel Ramos-Goñi $^{4,5}$

Published online: 6 October 2015

(c) Springer International Publishing Switzerland 2015

\section{Erratum to: Qual Life Res \\ DOI 10.1007/s11136-015-1086-4}

In the Original publication of the article, the mean value index has been published with an incorrect value in the abstracts part. The corrected line is "The mean index value, using the selected Uruguayan EQ-5D-5L value set, for the general population in Uruguay was 0.954 ".

The online version of the original article can be found under doi:10.1007/s11136-015-1086-4.

Juan Manuel Ramos-Goñi

juanmanuel.ramosgoni@gmail.com

1 Instituto de Efectividad Clínica y Sanitaria (IECS),

Buenos Aires, Argentina

2 Escuela de Salud Pública, Facultad de Medicina, Universidad de Buenos Aires, Buenos Aires, Argentina

3 Fondo Nacional de Recursos, Montevideo, Uruguay

4 The EuroQol Research Foundation, Rotterdam, The Netherlands

5 Red de Investigación en Servicios de Salud en Enfermedades Crónicas (REDISSEC), C/Calvario, 271, $1^{\mathrm{a}}$ IZQ,

38350 Tacoronte, Tenerife, Spain 